\title{
Beneficial microorganisms in agriculture: the future of plant growth-promoting rhizobacteria
}

\author{
Veronica M. Reis • Bruno J. R. Alves \\ Anton Hartmann • Euan K. James • Jerri E. Zilli
}

Received: 19 February 2020 / Accepted: 27 February 2020 / Published online: 10 March 2020

(C) Springer Nature Switzerland AG 2020

With the exception of water, fixed nitrogen is the most common limiting factor for crop productivity. Nitrogenous fertilisers currently sustain an estimated $40 \%$ of the current world population and consume approximately $2 \%$ of the world's annual energy supply. Although the demand for fixed nitrogen can be met by chemical fertilisers, anthropogenic disturbances to the nitrogen cycle have resulted in major environmental and economic impacts. At present, less than half of the nitrogen used by farmers is assimilated by crops. Excess nitrogen leaks into ecosystems, leading to significant effects on soil and water quality, biodiversity, and atmospheric pollution. Biological Nitrogen Fixation (BNF) provides a more sustainable alternative to the use of synthetic fertilisers, and although it is long known that legume crops can be exploited to provide $\mathrm{N}$ to cropping systems through their BNF ability, the possibility that non-legumes may also provide such a service has

Responsible Editor: Hans Lambers.

V. M. Reis $(\bowtie) \cdot$ B. J. R. Alves • J. E. Zilli

Embrapa Agrobiologia, Km 07- BR 465, Seropédica, RJ

23891-000, Brazil

e-mail: veronica.massena@embrapa.br

\section{A. Hartmann}

Faculty of Biology, Microbe-Plant Interactions,

Ludwig-Maximilian-University München, D 82151,

Planegg-Martinsried, Germany

E. K. James

The James Hutton Institute, Invergowrie, Dundee DD2 5DA, UK received less attention. In spite of this, there is increasing interest in utilizing the BNF potential of plants in the (for example) Poaceae family such as sugarcane, cereal and forage grasses, particularly in tropical and sub-tropical regions wherein they tend to receive substantially less mineral $\mathrm{N}$ additions to those in the northern hemisphere. In addition, the biofertilizer industry is expanding annually, again mostly in the tropics, but now increasingly in Europe and North America. Although biofertilizers often contain diazotrophs, such as Azospirillum, in consortia with other bacteria, their mode of action often does not rely on BNF, but instead their plant growth-promoting effects may be due to a range of attributes, such as production of auxins (and other hormones and non-hormones) leading to increased root growth and hence increased uptake of $\mathrm{N}$ from the soil, phosphate solubilization, siderophore production, and antagonism towards (mainly fungal) pathogens.

This special issue of Plant and Soil contains selected papers from the 16th Symposium on Nitrogen Fixation by Non-legumes which was held as a joint event with the Latin-American Workshop of PGPR - Plant Growth Promoting Rhizobacteria, in Foz do Iguaçu, Paraná State-Brazil, from 26 August to 1 September 2018. The original aim of this series of meetings was to highlight research into those $\mathrm{N}_{2}$-fixing systems (both free-living and symbiotic) that do not fall into the most widely-studied BNF system: the nodulating symbiosis between legumes and rhizobia. In recent years, however, the scope of the meetings has expanded to include 
research into plant growth-promoting rhizobacteria (PGPRs) and biofertilizers, regardless of their mode of action, although BNF and diazotrophic microorganisms remain a major part of the remit of the symposium series. This special issue of 13 papers reflects this diversity in subjects within the wider field of nonlegume BNF and PGPR research.

In total, the Symposium had 300 participants from 14 countries. Lectures were presented from national and international experts together with oral and poster presentations chosen from submitted abstracts by students and early career scientists over four days of activity. The important points addressed in this event were related to: 1) State of the art and perspectives of technological transfer of knowledge about beneficial microorganisms in agriculture with (2) evaluation of key mechanisms of interaction between plant beneficial diazotrophic bacteria and plants, and (3) the performance of these microorganisms to improve efficiency, and consequently increases in productivity / sustainability of agricultural systems. Within these main objective some more detailed points were also raised: a) development of methods to cultivate microbial species not yet described; (b) formulation of microbial consortia; c) emphasis on field trials for agronomic efficiency assessment; d) use of genetically modified microorganisms in agriculture; e) maintenance of national and international collections and exchange of biological assets.

Finally, we would like to honour the memory of one of our most esteemed and well-liked colleagues, Yoav Bashan, who was due to attend the Foz do Iguaçu symposium, but who unfortunately became seriously ill and subsequently passed away. The following obituary, which conveys the thoughts of all of us who knew Yoav Bashan, was penned by Drs. Maskit Maymon and Ann Hirsch (UCLA, California, USA).

Yoav Bashan (1951-2018).

Yoav Bashan, a preeminent figure in the field of Plant Growth-Promoting Bacteria (PGPB), died September 19, 2018 after a long illness.

Yoav was a descendent of a family that emigrated to Palestine from Eastern Europe during the nineteenth century. His parents, Avner (born Bonstein) and Sara Bashan were farmers specializing in growing grapes for the emerging wine industry. Perhaps this background in agriculture led to Yoav getting an undergraduate degree in Agronomy, followed by M.Sc. and Ph.D. degrees in Phytobacteriology and Plant Pathology from the Agriculture Faculty of the
Hebrew University of Jerusalem in Rehovot. He did his postdoctoral training in agricultural microbiology and environmental microbiology in Israel and the USA and was an Assistant Professor for two years (1985-1987) at The Weizmann Institute.

Yoav spent most of his career in Mexico, especially in La Paz, Baja California at CIBNOR (Environmental Microbiology Group, Northwestern Center for Biological Research). In Mexico, he did his most significant research and it is there where his career really flourished. Yoav's contributions were imminently practical and significantly helped his adopted country. Yoav coined the term PGPB, which is more general than the original description PGPR (Plant Growth-Promoting Rhizobacteria) penned by Joe Kloepper. He worked to restore mangrove ecosystems and used microalgae and their associated PGPBs to eliminate excess phosphorus and nitrogen from wastewater. He published numerous papers on both basic and applied research, and his research output was prodigious and important. Studies on soil restoration in Mexico, the most recent published in Land Degradation and Development in 2017, is just one of many examples.

In 2012, Yoav was recognized by the Congress of the State of Baja California Sur, Mexico for his outstanding scientific activities for the benefit of the people of the state. In 2013 he was awarded the Mexican National Prize in Biology of Soils, named after Dr. Jesús Caballero-Mellado, by the Mexican Society of Soil Science. In 2018 he received the highest scientific recognition in Mexico as emeritus professor from the Mexican National Research System.

In 2003, Yoav established the Bashan Foundation together with his wife Luz de-Bashan. The foundation provides free access to scientific literature, supports talented graduate students, who are pursuing a master or doctoral degree in developing countries and serves as a public platform for up-and-coming artists. The once virtual foundation is now housed in The Bashan Institute of Science (BIS) in Auburn, Alabama and is academically affiliated with Auburn University. The beautiful building and garden were designed and built by Yoav and Luz, and reflect their love and respect for nature.

Yoav was a man of many talents who dared to dream; he was an outstanding scientist and a gifted artist with a contagious passion for his work fueled by a sacred mission to create novel cutting-edge scientific advances 
to improve humanity's well-being while preserving and restoring the environment.

Yoav Bashan was Section Editor of Plant and Soil from June, 2014 onwards.

Yoav is buried in the garden of The Bashan Institute of Science in Auburn by a grove of young olives he helped plant shortly before his passing. He is survived by his children Neta, Noga and Lior, his grandchildren
Shaked, Ariel, Omer and Jehonatan and his wife Luz deBashan.

Ann Hirsch, Maskit Maymon.

Publisher's note Springer Nature remains neutral with regard to jurisdictional claims in published maps and institutional affiliations. 